\title{
Research on neutral-point potential control of a three-level inverter
}

\author{
Guangjie Fu, Xinpeng Li \\ School of Electrical and Information Engineering, Northeast Petroleum University, Heilongiiang Province, China
}

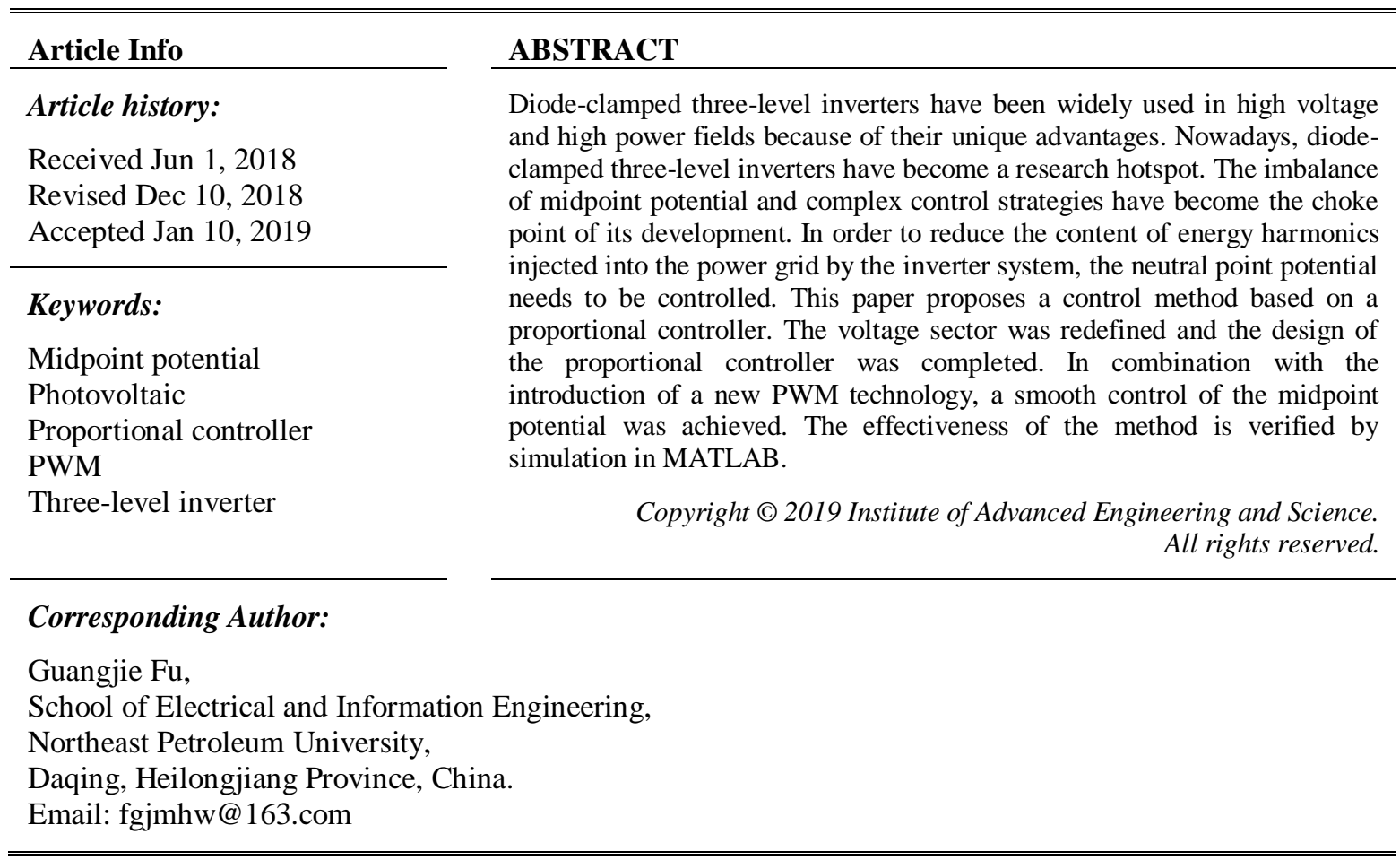

\section{INTRODUCTION}

With the ever-decreasing reserves of fossil energy, new energy sources are increasingly favored by people. The installed capacity of photovoltaic power generation is increasing, and photovoltaic gridconnected inverter technology has become a research hotspot [1]. Compared with two-level inverters, threelevel inverters have large output capacity, strong anti-interference, and small switching loss, which can improve the quality of the output waveform and reduce the harmonic content of the output [2]-[4] Due to these characteristics of the Neutral Point Clamped (NPC) type three-level inverter, it has been widely used in photovoltaic inverter grid-connected [5]-[6], and the midpoint potential control is one of its important research topics.

The commonly used midpoint potential control methods are hardware method and software method [7]-[10]. The hardware algorithm is to add a plurality of DC power supplies or increase DC capacitance on the DC side. The software algorithm controls the midpoint potential through the design of the control algorithm. Compared with the software method, the hardware method has high hardware cost and the software method is easy to implement [11]-[14]. Commonly used software controls include multi-carrier PWM method, specific harmonic elimination PWM method, and space vector PWM method. These methods have complicated operation or unstable DC-side current, which limits the quality of inverter output power [15]-[18]. This paper uses a proportional controller and a new PWM technology to control the midpoint potential. Finally, the effectiveness of the method is verified by simulation. 


\section{SYSTEM MODEL}

The inverter system is mainly composed of photovoltaic cells, NPC type three-level inverters and AC power grid. The structure of the inverter control system is shown in Figure 1.

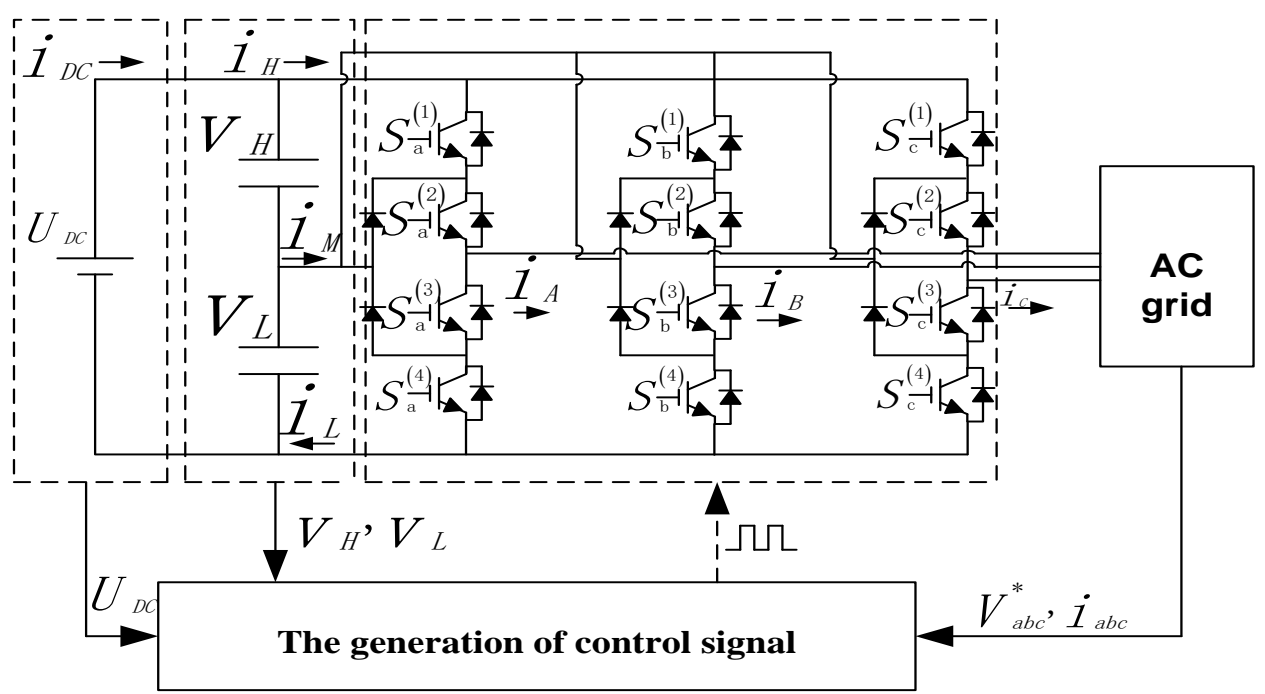

Figure 1. Inverter system control flow chart

\subsection{DC-link voltage control model}

As can be seen from Figure 1, each bridge of the NPC type three-level inverter includes four switches and two clamping diodes. The high-voltage side and the low-voltage side share the DC-link voltage. The voltages are respectively represented by $V_{H}$ and $V_{L}$, and the voltage at the end of the phase is represented by $V_{x}, \mathrm{H}$ and $\mathrm{L}$ respectively represent the states of different bridge arms. The definition of each state is shown in the following Table 1.

Table 1. Definition of leg status

\begin{tabular}{|c|c|c|c|c|c|}
\hline \multirow[b]{2}{*}{ Leg status } & \multicolumn{4}{|c|}{ switch status } & \multirow[b]{2}{*}{ Terminal voltage } \\
\hline & $S_{x}^{(1)}$ & $S_{x}^{(2)}$ & $S_{x}^{(3)}$ & $S_{x}^{(4)}$ & \\
\hline $\mathrm{H}\left(V_{H}\right)$ & $\mathrm{ON}$ & ON & OFF & OFF & $\mathrm{Udc} / 2$ \\
\hline $\mathrm{L}\left(V_{L}\right)$ & OFF & OFF & $\mathrm{ON}$ & ON & $-\mathrm{Udc} / 2$ \\
\hline
\end{tabular}

Where, $X \in\{a, b, c\}$.

Therefore, the voltage of each phase can be defined as follows:

$$
V_{X}=\delta_{H} V_{H}-\delta_{L} V_{L}, X \in\{\alpha, \beta, \gamma\}
$$

Where $\delta_{H} 、 \delta_{L}$ respectively represent the working periods of the bridge in the high and low states,$\{\alpha, \beta, \gamma\}$ represents the working period of bridge $\{a, b, c\}$, and the working period of each bridge must satisfy the condition: $\delta_{H}+\delta_{M}+\delta_{L}=1$.

$$
-\mathrm{V}_{L} \leq V_{x} \leq V_{H}, x \in\{a, b, c\}
$$

Where $V_{H}$ and $V_{L}$ can be expressed as follows: 


$$
\left\{\begin{array}{l}
\frac{d V_{H}}{d t}=\frac{i_{D C}-i_{H}}{C} \\
\frac{d V_{L}}{d t}=\frac{i_{D C}-i_{L}}{C}
\end{array}\right.
$$

By subtracting the two ends of the formula above :

$$
\frac{d V_{M}}{d t}=\frac{i_{M}}{C}
$$

Where $V_{M}=V_{H}-V_{L}, i_{M}=i_{H}-i_{L}$.

The final DC-link current can be expressed as follows:

$$
\left\{\begin{array}{l}
i_{H}=\alpha_{H} i_{a}+\beta_{H} i_{b}+\gamma_{H}{ }^{i C} \\
i_{L}=-\left(\alpha_{L} i_{a}+\beta_{L} i_{b}+\gamma_{L^{i} C}\right)
\end{array}\right.
$$

From equation (4), it can be seen that the imbalance of the neutral point potential can be controlled by $i_{M}$, so that it can be controlled by an appropriate PWM technique using a proportional controller. Therefore, the binary definition of the voltage sector is introduced in this paper, and a new parameter $\{u, v, w\}$ is introduced as shown in Table 2.

Table 2. Terminal index of each phase

\begin{tabular}{lllllll}
\hline$\sigma v$ & I & II & III & IV & V & VI \\
\hline$U$ & $\mathrm{a}$ & $\mathrm{c}$ & $\mathrm{b}$ & $\mathrm{a}$ & $\mathrm{c}$ & $\mathrm{b}$ \\
$V$ & $\mathrm{~b}$ & $\mathrm{a}$ & $\mathrm{c}$ & $\mathrm{b}$ & $\mathrm{a}$ & $\mathrm{c}$ \\
$\boldsymbol{W}$ & $\mathrm{c}$ & $\mathrm{b}$ & $\mathrm{a}$ & $\mathrm{c}$ & $\mathrm{b}$ & $\mathrm{a}$ \\
\hline
\end{tabular}

Where $V_{u v}$ represents the maximum voltage value, and $V_{v w}$ and $V_{w u}$ are always opposite to $V_{u v}$. Therefore, from formula (1):

$$
V_{x}=\delta_{H} V_{H}-\delta_{L} V_{L},-V_{L} \leq V_{x} \leq V_{H}
$$

Where $X \in\{u, v, w\}, \delta \in\{\varphi, \psi, \xi\}, \delta$ represents the working period of X. Assuming that the $\mathrm{H}$ and $\mathrm{L}$ states of each bridge cannot occur in the same sampling interval, the above equation becomes:

$$
\delta_{H}=\frac{\left|V_{x}\right|+V_{x}}{2 V_{H}}, \delta_{H}=\frac{\left|V_{x}\right|-V_{x}}{2 V_{L}}
$$

Formula (5) becomes:

$$
\left\{\begin{array}{l}
i_{H}=\varphi_{H^{i}} i_{u}+\psi_{H^{i}}+\xi_{H^{i}} i_{w} \\
i_{L}=-\left(\varphi_{L^{i}} i+\psi_{L^{i}}+\xi_{L} i_{w}\right)
\end{array}\right.
$$

From equations (4) and (8), the following relationship can be obtained: 


$$
\frac{d x}{d t}=B u
$$

Where $x=V_{M}, B=\frac{1}{C}\left[-i_{u}, i_{u},-i_{v}, i_{v},-i_{\tau}, i_{\tau}\right] u=\left[\varphi_{H}, \varphi_{L}, \psi_{H}, \psi_{L}, \xi_{H}, \xi_{L}\right]^{T}$.

From the analysis, it can be seen that for a given reference voltage, the DC-link voltage can be balanced by properly adjusting the sum.

\section{NPC INVERTER MIDPOINT POTENTIAL CONTROL}

In this paper, the proportional control and a suitable PWM technology are combined to realize the smooth control of the midpoint potential of the diode clamp type three-level inverter, avoiding the unnecessary jitter in the midpoint potential adjustment process. In order to avoid the midpoint voltage fluctuation problem that arises in the control process of the traditional voltage control method, two additional currents $i_{S}$ and $i_{P}$ are introduced, where $i_{P}$ represents the equivalent current source current, and $\boldsymbol{i}_{S}$ is determined by $i_{P}$ and $i_{M}$. The definition of $i_{P}$ is given below, $i_{M}$ can be obtained from the operation of the midpoint voltage through the proportional controller, where the proportionality factor $k$ is determined by the bandwidth and capacitance of the DC link. The control flow diagram of the control method is shown in Figure 2.

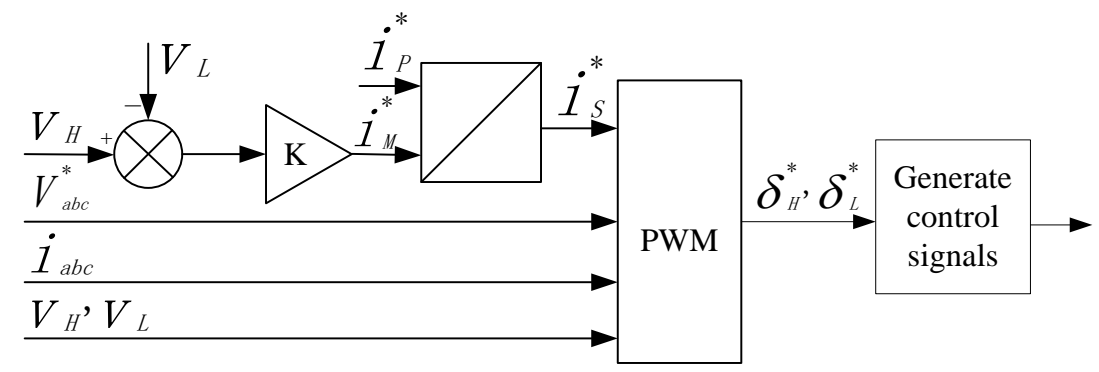

Figure 2. Control flow diagram based on proportion

Substituting equation (7) into equation (8):

$$
\left\{\begin{array}{l}
\boldsymbol{i}_{H}=\frac{1}{2 V_{H}}\left(\sum_{x}\left|V_{x}\right| \boldsymbol{i}_{x}+\sum_{x} V_{x} \boldsymbol{i}_{x}\right) \\
\boldsymbol{i}_{L}=-\frac{1}{2 V_{L}}\left(\sum_{x}\left|V_{x}\right| \boldsymbol{i}_{x}-\sum_{x} V_{x} \boldsymbol{i}_{x}\right)
\end{array}\right.
$$

Based on this, introduce two DC-link currents $\boldsymbol{i}_{P}$ and $\boldsymbol{i}_{S}$, their definitions are as follows:

$$
\left\{\begin{array}{l}
\boldsymbol{i}_{P}=V_{H} \boldsymbol{i}_{H}+V_{L} \boldsymbol{i}_{L}=\sum V_{x} \boldsymbol{i}_{x} \\
\boldsymbol{i}_{s}=V_{H} \boldsymbol{i}_{H}-V_{L} \boldsymbol{i}_{L}=\sum\left|V_{x}\right| \boldsymbol{i}_{x}
\end{array}\right.
$$

Where $\boldsymbol{i}_{P}$ represents the equivalent current source current, which is proportional to the active power, but $\boldsymbol{i}_{S}$ is the auxiliary current determined by $\boldsymbol{i}_{P}$ and $\boldsymbol{i}_{M}$, and the relationship is as follows:

$i_{S}^{*}=\left(V_{H}-V_{L}\right) \cdot i_{P}^{*}+\left(2 V_{H} V_{L}\right) \cdot i_{M}^{*}$ 
Therefore, it does not affect the power exchange between the photovoltaic system and the main AC grid, and $i_{S}$ can be set according to the need of the DC-link equivalent voltage. A suitable $i_{M}^{*}$ is as follows:

$i_{M}^{*}=-K V_{M}$

In order to achieve proper dynamic performance, it is necessary to set the $\mathrm{K}, \boldsymbol{i}_{M}^{*}$ can be set as $\boldsymbol{i}_{M}$, especially when compared with the DC-link voltage its change is almost instantly completed. The bandwidth of the unbalanced voltage control loop of DC link is set as $f_{D C}$, K can be expressed as follows:

$k=2 \pi f_{D C} C$

$\mathrm{K}$ and $i_{S}^{*}$ are deduced from the above analysis.

\subsection{PWM control technology}

In order to realize the control of the midpoint potential of the inverter, a suitable PWM technique is needed, and tracking of $\boldsymbol{i}_{S}$ can be achieved through this PWM technique. The flow chart of PWM control technology is shown in Figure 3.

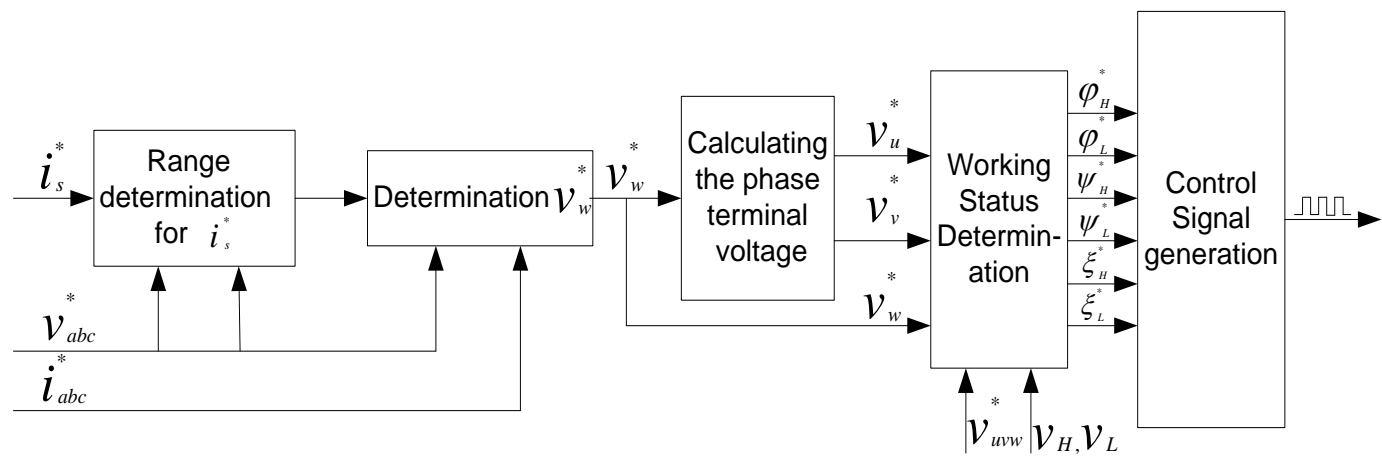

Figure 3. Ratio-based PWM control flow diagram

Considering the reference chain voltages of $\mathrm{u}, \mathrm{v}$, and w cells, which can be expressed as follows:

$V_{u v}^{*}=V_{u}-V_{v}, V_{v w}^{*}=V_{v}-V_{w}, V_{w u}^{*}=V_{w}-V_{u}$

It can be derived from the above formula:

$V_{u}=-V_{w u}^{*}+V_{w}, V_{v}=V_{v w}^{*}+V_{w}$

By substitution of (16) to (6):

$\mathrm{V}_{w, \text { min }} \leq V_{w} \leq V_{w, \text { max }}$

Where: 


$$
\left\{\begin{array}{l}
V_{w, \min }=\max \left\{V_{w u}^{*},-V_{v w}^{*}\right\}-V_{L} \\
V_{w, \max }=\min \left\{V_{w u}^{*},-V_{v w}^{*}\right\}+V_{H}
\end{array}\right.
$$

It can be determined that the setting of the reference voltage can be realized for any $V_{M}$ that meets the requirements, and by substitution of (17) to (11):

$$
\left\{\begin{array}{l}
\boldsymbol{i}_{P}=-V_{w u}^{*} \boldsymbol{i}_{u}+V_{v w}^{*} \boldsymbol{i}_{v}+V_{w}\left(\boldsymbol{i}_{u}+i_{v}+i_{w}\right) \\
\boldsymbol{i}_{S}=\left|-V_{w u}^{*}+V_{w}\right| \cdot \boldsymbol{i}_{u}+\left|V_{v w}^{*}+V_{w}\right| \boldsymbol{i}_{v}+\left|V_{w}\right| \cdot \boldsymbol{i}_{w}
\end{array}\right.
$$

Therefore, assuming that the sum of the phase currents is equal to zero, it can be found that in the the three-phase system with isolated star connection, the change of $\boldsymbol{i}_{P}$ does not depend on $V_{M}$. Therefore, $i_{S}$ can control $V_{M}$ according to the demand of the DC-link voltage without affecting the energy exchange between the photovoltaic system and the main $\mathrm{AC}$ grid.

For the control of $\boldsymbol{i}_{S}$ to be implemented, voltage and current sectors need to be considered. In the parity sector, (18) can be changed to:

$$
\left\{\begin{array}{l}
V_{w, \text { min }}=-V_{w w}^{*}-V_{L}, V_{w, \text { max }}=V_{w u}^{*}+V_{H} \\
V_{w, \text { min }}=V_{w u}-V_{L}, V_{w, \text { max }}=-V_{w w}+V_{H}
\end{array}\right.
$$

Based on the value of each $\left(\delta_{v}, \delta_{i}\right)$ in (20), the alternative relation of $i_{S}$ and $V_{M}$ can be determined. It can be seen that the minimum and maximum values of $i_{S}$ that can be seen from here are usually in correspondence with $V_{w}^{+}$or $V_{w}^{-}$, and they are defined as:

$$
\left\{\begin{array}{l}
V_{w}^{(+)}=\max \left\{V_{w u}^{*},-V_{v w}^{*}\right\} \\
V_{w}^{(-)}=\min \left\{V_{w u}^{*},-V_{v w}^{*}\right\}
\end{array}\right.
$$

Therefore, if there is at least one of $V_{M}$ is in the interval $\left[V_{w, \text { min }}, V_{w, \text { max }}\right]$, it means that the plateau region of $i_{S}$ will appear. As previously assumed, since the sum of the currents of the phases in this region is equal to zero, the change of $V_{M}$ does not affect the value of $i_{S}$. When $V_{W}$ is equal to zero, the maximum or minimum of $i_{S}$ in current sector II and $\mathrm{V}$ occurs. In this case, a given $i_{s}^{*}$ may correspond to two different values: $V_{\mathrm{w}}^{*}$ and $\tilde{V}_{w}^{*}$. To ensure linear control of $i_{S}$ over its full range and that $V_{\mathrm{w}}^{*}$ is within the $V_{\mathrm{w}}^{*}$ time period. $V_{\mathrm{w}}^{*}$ should be selected. In conclusion, for the given $V_{M}$ and $i_{S}^{*}$, we can choose $V_{\mathrm{w}}^{*}$ according to the analysis above, all the phase terminal voltages are calculated by formula (16), and the duty cycle of each bridge in the $\mathrm{H}$ and $\mathrm{L}$ states can be calculated by (7).

\section{SIMULATION ANALYSIS}

In order to verify the feasibility of the proposed method, a system simulation model was set up in MATLAB. Set the DC-link voltage to $1.5 \mathrm{KV}$, the switching frequency to $10 \mathrm{KHz}$, the sampling interval to 100us, the minimum pulse width to 0.8us, the power supporting the photovoltaic system is 30KVA, and the high and low side capacitor voltages of DC-link are set to $0.6 \mathrm{pu}$ and 0.4 respectively. The simulation results are as follows. Figure 4 and Figure 5 show the changes of the midpoint voltage and current respectively. Figure 6 and Figure 7 show the voltage and current waveforms of the inverter input to the power grid respectively. The simulation results show that the method achieves the smooth control of the midpoint potential. At lower voltage and current ripples, 
the stability of the midpoint potential control is ensured when the power changes, ensuring the quality of the electrical energy input to the grid. Harmonic detection output by inverter is controlled within 0.04 .

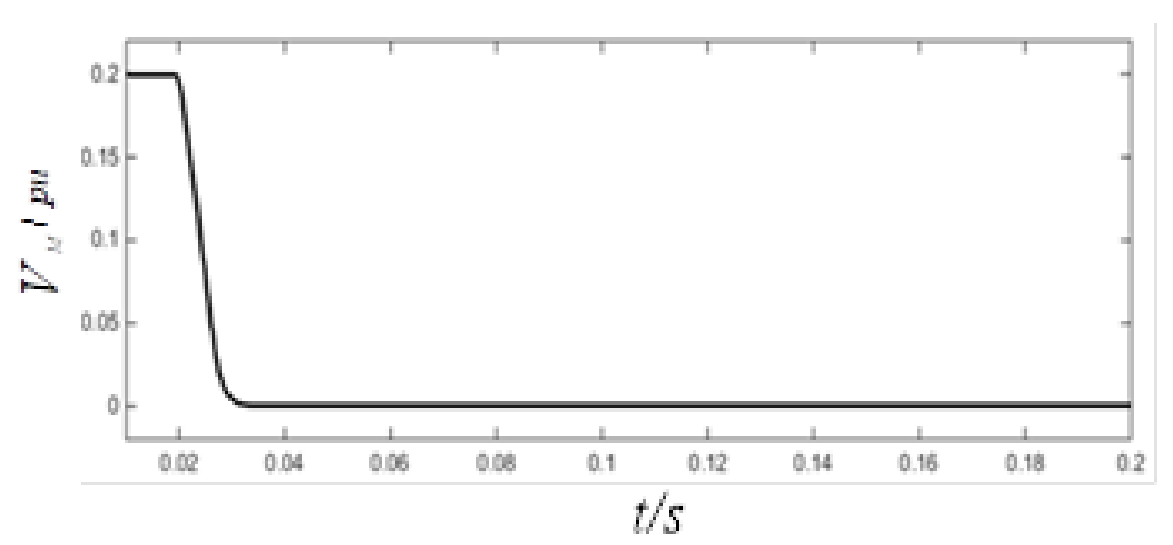

Figure 4. Midpoint potential change curve

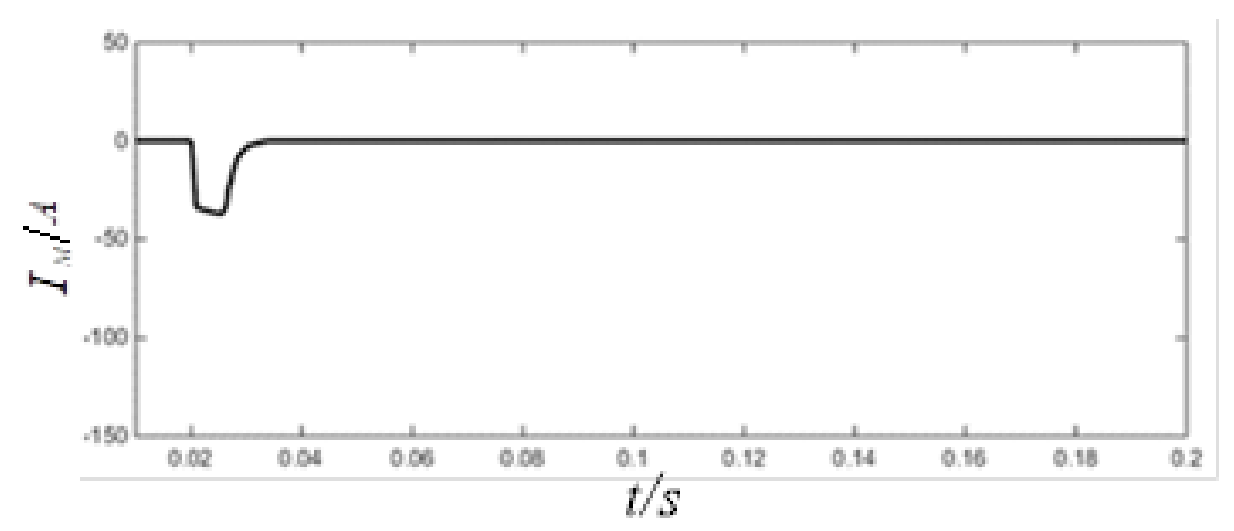

Figure 5. Midpoint current curve

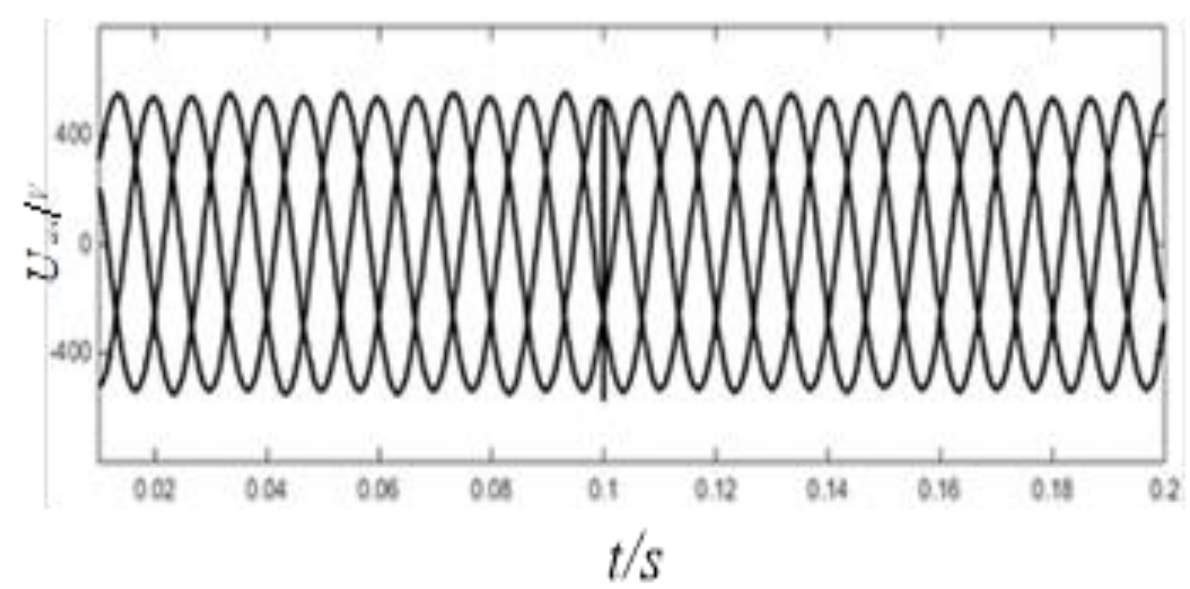

Figure 6. AC line voltage curve 


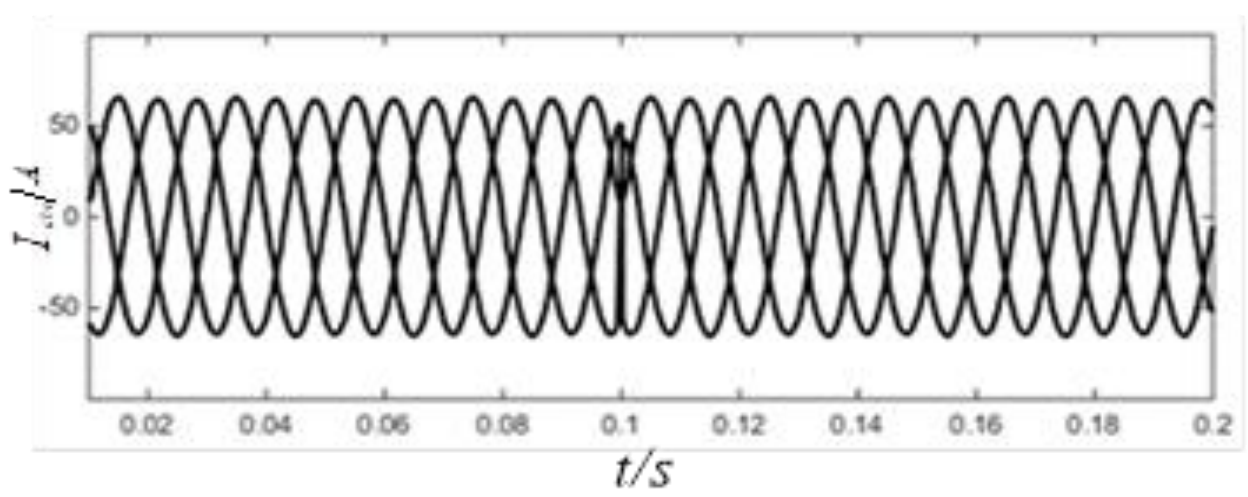

Figure 7. AC phase current curve

\section{CONCLUDING REMARKS}

The scheme based on the proportional controller proposed in this paper, through the design of the proportional controller, combined with a new PWM technology to control the midpoint potential. The simulation results show that the method effectively suppresses the drift of the DC side capacitor voltage, reduces the ripple of voltage and current in the output power, and realizes the effectiveness of the midpoint potential control, and the harmonics input by the inverter to the grid energy are also within acceptable limits.

\section{ACKNOWLEDGMENTS}

Sponsored by Fund: Northeast Petroleum University Graduate Innovation Project (JYCX_CX06_2018)

\section{REFERENCES}

[1] Irwanto, M., et al. "Effect of Maximum Voltage Angle on Three-Level Single Phase Transformerless Photovoltaic Inverter Performance." Telkomnika Indonesian Journal of Electrical Engineering 12.8(2014).

[2] Chun-Yu, X. U., and M. Liu. "Study of Neutral-point Potential Control Method for Three-level Inverter."Electric Drive(2013).

[3] Xing, L. I., et al. "A New Neutral Voltage Balance Control Strategy of Three-level NPC Inverter." Journal of Power Supply (2016).

[4] Ibrahim, Zulkifilie Bin, et al. "Comparative Analysis of PWM Techniques for Three Level Diode Clamped Voltage Source Inverter." International Journal of Power Electronics \& Drive Systems 5.1(2014).

[5] Vaseee, Srinu, and B. V. Sankerram. "Voltage Balancing Control Strategy in Converter System for Three-Level Inverters." International Journal of Electrical \& Computer Engineering 3.1(2013):7-14.

[6] Cai, Jiang, et al. "A Neutral-point Voltage Balancing Control Method for Three-level Neutral-point-clamped Inverter." Automation of Electric Power Systems38.7(2014):88-94.

[7] Hashir, Shaziya, Jebin Francis, and R. Sreepriya. "A novel hybrid PWM method for DC-link voltage balancing in a three level neutral point clamped inverter." In 2018 International Conference on Power, Signals, Control and Computation (EPSCICON), pp. 1-6. IEEE, 2018.

[8] Gang, Liu, Wang Dafang, Wang Miaoran, Zhu Cheng, and Wang Mingyu. "Neutral-Point Voltage Balancing in Three-Level Inverters Using an Optimized Virtual Space Vector PWM With Reduced Commutations." IEEE Transactions on Industrial Electronics 65, no. 9 (2018): 6959-6969.

[9] Kashif, Muhammad, et al. "A Study of Three-Level Neutral Point Clamped Inverter Topology." Telkomnika Indonesian Journal of Electrical Engineering 12.8(2014).

[10] Zhong, Wan Sheng, et al. "Control Strategy of Neutral-point Potential Balancing in Three-level Inverter." Electric Drive (2014).

[11] Cao, Guofeng, R. Wang, and R. Meng. "Integrated control strategy of neutral point potential balance in three-level inverter." Modern Electronics Technique (2017).

[12] LI Xing, JIN Bin, XIONG Ming, WANG Jianlin. A New Neutral Voltage Balance Control Strategy of Three-level NPC Inverter[J], Journal of Power Supply, 2017,40(16):165-169

[13] J. S. Lee and K. B. Lee, "New Modulation Techniques for a Leakage Current Reduction and a Neutral-Point Voltage Balance in Transformerless Photovoltaic Systems Using a Three-Level Inverter," in IEEE Transactions on Power Electronics, vol. 29, no. 4, pp. 1720-1732, April 2014.

[14] Gnanasundari, M., M. Rajaram, and Sujatha Balaraman. "Natural balancing of the neutral point potential of a threelevel inverter with improved firefly algorithm." Journal of Power Electronics. 16, no. 4 (2016): 1306-1315. 
[15] W Keli, X Changliang, Z Yun. Common-mode voltage suppression for neutral-point-clamped three-level inverter. Transactions of China Electrotechnical Society,30(24), pp.110-117.

[16] Jianguo, L., Wenbin, H. and Fuyun, W. Low frequency oscillation suppression scheme of neutral-point voltage for neutral point clamped three-level inverter. Proceedings of the CSEE, 35(19), pp.5039-5049.

[17] Karthikeyan, D., R. Palanisamy, K. Vijayakumar, A. Velu, and D. Selvabharathi. "Parallel Connected VSI Inverter using Multi-carrier based Sinusoidal PWM Technique. "Telkomnika 15, no. 4 (2017): 1625-1631.

[18] Tong, Jun, Jianwei Qiao, Lijun Liu, Yao Lu, and Qian Zhang. "Neutral point potential balance control strategy of three level inverter." In 2018 13th IEEE Conference on Industrial Electronics and Applications (ICIEA), pp. 13571361. IEEE, 2018. 